\title{
Redistribution of vitamin $A$ in tissues of rats with imposed chronic confinement stress
}

\author{
BY KIWAO NAKANO AND AKIHITO MORITA \\ Department of Nutritional Regulation, The Research Institute for Biochemical Regulation, \\ Nagoya University, Chikusa, Nagoya 464, Japan
}

(Received 14 April 1981-Accepted 22 January 1982)

\begin{abstract}
1. The effect of confinement stress on the metabolism of vitamin A was studied in rats by following changes in tissue distribution of the vitamin for $29 \mathrm{~d}$. In order to minimize predicted errors which might result from fluctuation of vitamin A intake, the effect of the stress was investigated in rats fed on a vitamin A-free diet.

2. Daily stress for $6 \mathrm{~h}$ induced an enlargement of the adrenals with a concomitant involution of the thymus and spleen, values returning to normal within $11-15 \mathrm{~d}$.

3. The stress caused an immediate decrease in the content of vitamin $A$ in serum.

4. Feeding rats a vitamin A-free diet resulted in a significant increase in the vitamin A content of the kidney. Imposing stress on these rats inhibited markedly the increase in kidney vitamin A content.

5. The stress produced no appreciable change in levels of the vitamin in the liver and testes.

6. There was a preferential accumulation of the vitamin in the adrenals of the stress-imposed rats even though they were fed on a vitamin A-free diet.

7. In conclusion, the results of the present study demonstrated that chronic immobilization stress produced marked tissue-dependent changes in their vitamin $\mathrm{A}$ content.
\end{abstract}

There are many reports of altered vitamin A status in animals and humans produced by acute or chronic stress conditions. Thus, it has been shown that blood level, liver content or urinary output of vitamin A are influenced by imposing a variety of stressful stimuli such as physically- or chemically-induced fever (Aron et al. 1946; Kagan \& Kaiser, 1955), surgical operation (Ramsden et al. 1978), myocardial infarction (Ramsden et al. 1978), emotional stress (Hepner \& Maiden, 1971), physical training (Barisov, 1977), burn injury (Rai \& Coutemanche, 1975) and heat or cold exposure (Page et al. 1959; Odagiri \& Koyanagi, 1961 ; Porter \& Masoro, 1961; Sundaresan et al. 1967). Ershoff $(1950,1952)$ and Sundaresan et al. (1967) proposed that the vitamin A requirement is increased by prolonged exposure of rats to cold-exposure stress, based on the reduced survival time of vitamin A-deficient animals. However, the mechanism regulating the previously-mentioned processes is now only partly understood.

The present study was carried out to obtain basic knowledge about the nature of the regulatory mechanism of vitamin A metabolism which would be affected in the stressed animals. Confinement stress was employed as a stimulus since to the best of our knowledge no information is available on the effect of this type of stress on vitamin A metabolism in animals and humans, although it has been used often in experimental medicine and veterinary science in the hope that it will produce the purest stress of frustration by depriving the animals of their liberty to move about (Selye, 1976). The effect of chronic application of this stressor was studied in order to follow changes in the metabolism of vitamin A during early and later stages of adaptation of the animals to the stress condition.

\section{EXPERIMENTAL}

Animals. Male albino rats of the Wistar strain (Shizuoka Experimental Animals and Agricultural Cooperative, Hamamatsu, Japan) initially weighing $50 \mathrm{~g}$ were used.

Diets. The vitamin A-free diet contained (g/kg): 250 vitamin A-free casein (Wako Pure 
Chemicals Industries, Ltd., Osaka, Japan), 20 maize oil, 8.5 water-soluble vitamin mixture (Harper, 1959), 0·10 all-rac- $\alpha$-tocopherol acetate, $7 \cdot 5 \mu \mathrm{g}$ ergocalciferol, 20 cellulose powder, 40 salt mixture (Harper, 1959), 660 maize $\alpha$-starch. The vitamin A-supplemented diet was prepared by adding retinyl acetate to the vitamin A-free diet, $3.06 \mathrm{mg} / \mathrm{kg}$ diet. Both diets were prepared fresh weekly.

Experimental design. Rats were housed in individual aluminium and stainless-steel cages with wire floors in a temperature-regulated $\left(22 \pm 2^{\circ}\right)$, light-controlled (lights on $07.00-19.00$ hours) room. Rats were given free access to water and to the experimental diets. All 115 rats were allowed $7 \mathrm{~d}$ of acclimatization to the laboratory conditions before use in experiments, during which time they were fed on a vitamin A-supplemented diet. Five rats were killed on the 8th day to obtain the starting values. The remaining animals were divided into two groups. The rats of the first group were kept on a vitamin A-supplemented diet $(+\mathrm{A}$ control group). The remaining rats were transferred to a vitamin A-free diet and divided into two sub-groups. The animals of one sub-group.were subjected to stress ( $\mathrm{A}$ stress group), while the rats of the other sub-group were maintained in home cages ( $-\mathrm{A}$ control group). As described previously, the effect of stress was examined by comparing these two groups of rats fed on a vitamin A-free diet.

Stress procedure. Experimental animals were wrapped twice daily for $3 \mathrm{~h}$ each (morning 07.00-10.00 hours, and evening 16.00-19.00 hours) with a fine mesh (no. 150) stainless-steel screen which was closed permanently by folding the front edge and the rear edge was free for introducing and removing the rats. After the rat was in place the free edge was clamped with a paper clip. Two sizes of screens, one approximately $95 \times 145 \mathrm{~mm}$ and the other $115 \times 190 \mathrm{~mm}$ were used depending on how much the size of the animals increased during the experimental period. Each animal in its screen was placed in an upright position against the wall inside its own cage. The control rats were left undisturbed in separate cages. Imposing the stress on the rats was started on the same day that the vitamin A-free diet regimen was begun. Animals were killed by decapitation, usually just after the morning stress period. Blood was collected in a glass centrifuge-tube and then centrifuged. The serum thus obtained was stored at $-80^{\circ}$ for analysis of vitamin A. The liver, kidneys, testes, thymus, spleen and adrenal glands were removed immediately, and rinsed with ice-cold saline $(9 \mathrm{~g}$ sodium chloride/l). After adhering saline was blotted off with filter paper, the tissue was weighed and whole organs or a part $(0.5-1.5 \mathrm{~g}$, depending on the vitamin A status of each rat) were put into a small centrifuge-tube fitted with a condenser and containing $1 \mathrm{ml}$ ethanol and $0.75 \mathrm{ml}$ potassium hydroxide $(500 \mathrm{~g} / \mathrm{l})$. Each tube was wrapped with aluminium foil to shelter it from light and then incubated for $40 \mathrm{~min}$ at $60-70^{\circ}$ with shaking to hydrolyze the retinyl esters. The adrenal glands from five animals were pooled for analysis of the vitamin: Subsequent operations were performed in a dark-room with a dim red light. After each tube was cooled rapidly to room temperature, $1 \mathrm{ml}$ water and $5 \mathrm{ml}$ spectrophotometric-grade hexane were added and the contents were mixed vigorously for 1 min using a vortex mixer. After centrifugation, a portion of the hexane layer was used for fluorometric measurement of vitamin A using the correction formula method of Thompson et al. (1971). A serum sample $(0.4 \mathrm{ml})$ was mixed with $1 \mathrm{ml}$ water, $1 \mathrm{ml}$ ethanol and $5 \mathrm{ml}$ hexane. A portion of the hexane layer was used for analysis of vitamin A (Thompson et al. 1971). Some kidney samples were also assayed for vitamin A by the trifluoroacetic acid method of Dugan et al. (1964); good agreement between the results was found. The Student's $t$ test was used to estimate the significance of differences between the stressed and the control group (Snedecor \& Cochran, 1967). 


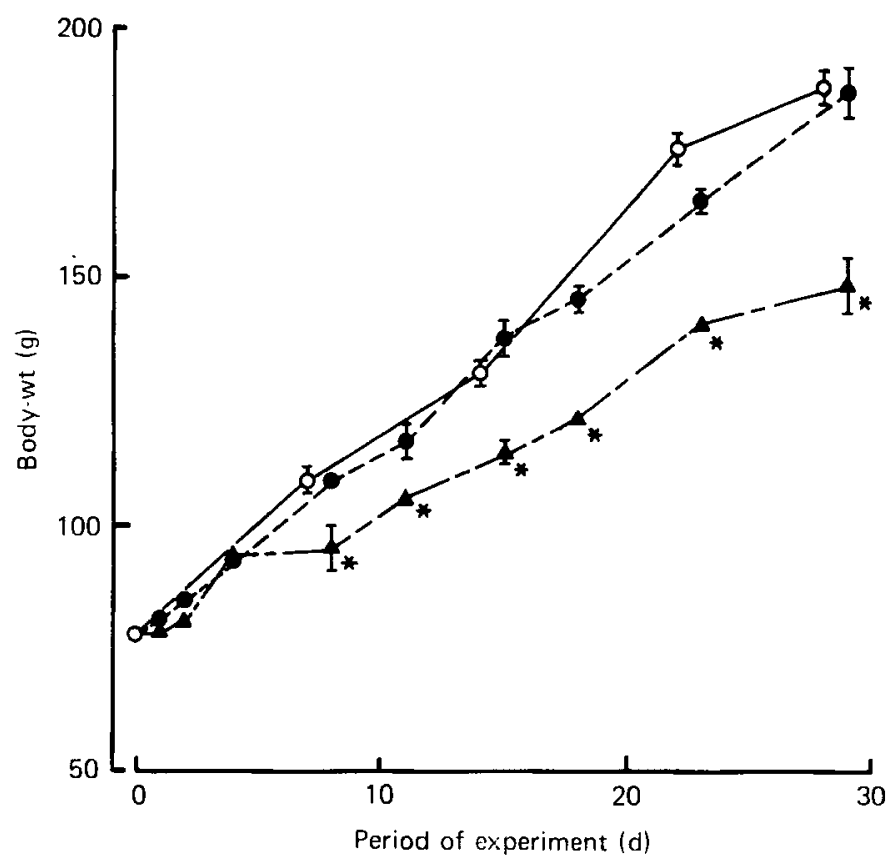

Fig. 1. The effect of $6 \mathrm{~h}$ of daily chronic immobilization on body-weight of young adult male rats. (O), Rats fed on a vitamin A-containing diet (+A control); (O), rats fed on a vitamin A-free diet ( $-A$ control); (A), rats fed on a vitamin A-free diet and subjected to confinement stress ( $-\mathbf{A}$ stress). Feeding regimen of the vitamin A-free diet was started on day 0 of the experiment. The points are mean values with their standard errors, represented by vertical bars, for five rats. The differences between values for - A control group and $-\mathrm{A}$ stress group were significantly different: ${ }^{*} P<0.05$.

\section{RESULTS}

\section{Body-and organ weight}

Fig. 1. illustrates the cumulative influence of $6 \mathrm{~h}$ daily confinement stress on total body-weight. No significant difference was observed in the growth rate of the + A control group and that of the $-\mathrm{A}$ control group. These results are consistent with those obtained by others in that the rats fed on a vitamin A-free diet continued to grow normally for approximately $50-60 \mathrm{~d}$. On the other hand, growth of the stressed animals was retarded during the initial $8 \mathrm{~d}$ of exposure to the stressor. The growth rate of these animals thereafter caught up to that of the -A control group. These results indicate that the stressed animals had adapted to the stress condition during this period.

Vitamin A-free diet also caused no appreciable change in the relative weight of adrenal glands, thymus and spleen compared with those of rats fed on a vitamin A-supplemented $\operatorname{diet}($ Table 1). Adrenal weight reached a maximum $(+20 \%)$ on the 4 th $\mathrm{d}$ after the initiation of immobilization and the difference from the $-A$ control rats remained significant through the last day of the experiment. The relative weight of the thymus fell to a minimum $(-22 \%)$ on day 4; thereafter these values tended to return toward those of the - A control group, which also began to involute after $10 \mathrm{~d}$. This seems to be so-called age-dependent atrophy of the organ. The spleen also shows a diminution of size starting on the first day of exposure to confinement stress, the greatest decline, $-16 \%$, being observed on the 4 th $d$, after which time the values remained stable. These changes have been shown to be essentially the same regardless of the nature of the systemic stressor used: they seem to be the typical manifestations of the general adaptation syndrome (Selye, 1946). 


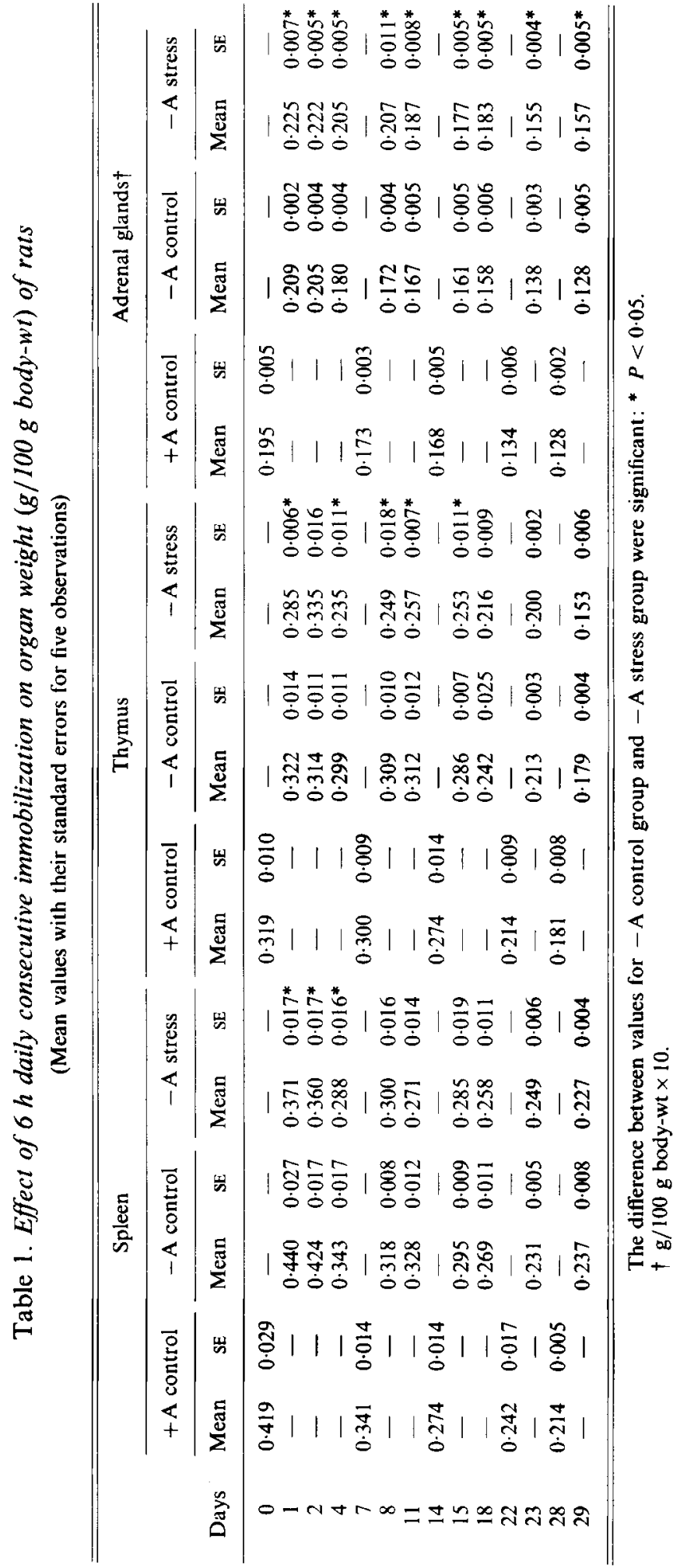




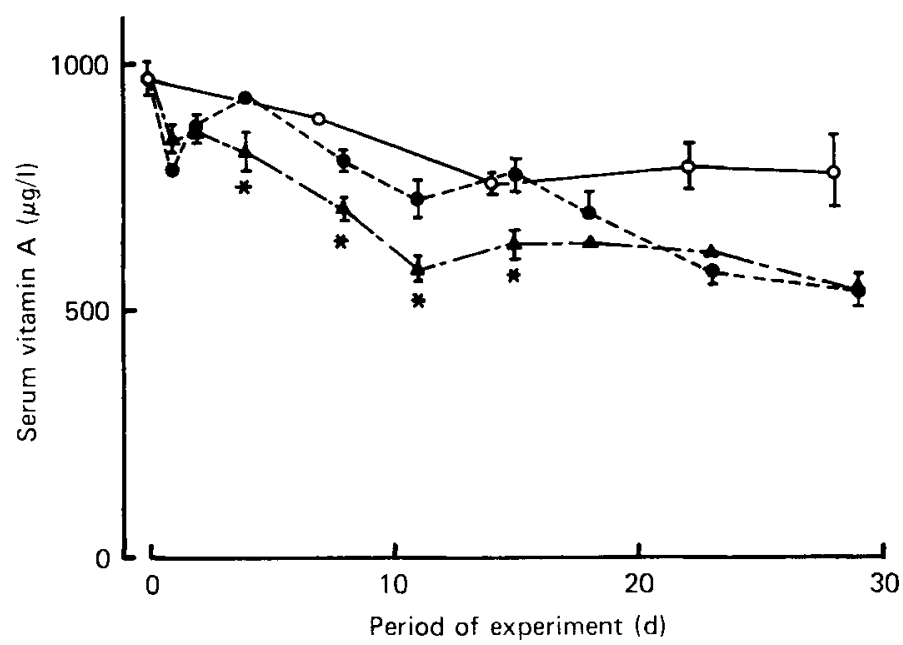

Fig. 2. The effect of $6 \mathrm{~h}$ of daily chronic immobilization on serum concentration of vitamin A. (O), $+\mathrm{A}$ control group; (O), - A control group; (A). - A stress group. The points are mean values with their standard errors, represented by vertical bars, for five rats. The differences between values for $-A$ control group and $-\mathrm{A}$ stress group were significantly different: ${ }^{*} P<0.05$.

\section{Tissue vitamin A}

Changes in the serum concentration of vitamin $A$ in each group are shown in Fig. 2. There was essentially no difference in it between the $-A$ control group and the $+A$ control rats until the 15th $d$ after initiation of the diets, but thereafter it began to decline in the former. These results are consistent with the generally-accepted belief that rats have a homoeostatic control mechanism for maintaining blood levels of vitamin $A$ within a narrow range despite a widely-varying dietary supply of the vitamin (Underwood et al. 1979). Immobilization for $6 \mathrm{~h}$ produced a slight but significant depression in blood levels of vitamin A during the initial $15 \mathrm{~d}$ of the experiment, after which the values became comparable to those in the -A control rats since the levels began to decrease after $15 \mathrm{~d}$ of this diet (Fig. 2).

As shown in Fig. 3(a), feeding rats a vitamin A-free diet resulted in a prompt decline in the hepatic content of vitamin A, only approximately one-fortieth of its initial content remained after $29 \mathrm{~d}$. Immobilization for 6 h provoked no further change in hepatic content of the vitamin.

The renal levels of vitamin A were elevated gradually in the rats fed on a vitamin A-free diet, the values reaching a plateau on the 18 th $\mathrm{d}$ (Fig. $3(b)$ ). In the +A control group the values remained stable throughout the experiment. These results agree with those obtained in a previous study (High, 1954) and those obtained by ourselves (Morita and Nakano, unpublished results). This increase in renal content of vitamin A occurring in the vitamin A-depleted rats was markedly inhibited during the first $7 \mathrm{~d}$ of exposure to immobilization. However, despite the unchanged schedule of restraint, it resumed at an accelerated rate after that, the difference from the $-\mathrm{A}$ control group remaining significant until the 23rd $\mathrm{d}$ of the experiment. These changes in the renal content of vitamin A are comparable with those in the weight of thymus and spleen (Table 1), suggesting that they are also manifestations of the general adaptation syndrome.

The results in Fig. 3(c) show that confinement stress failed to influence substantially the content of vitamin $A$ in the testis.

As shown in Fig. 3(d), the content of vitamin A in the adrenal glands increased gradually 


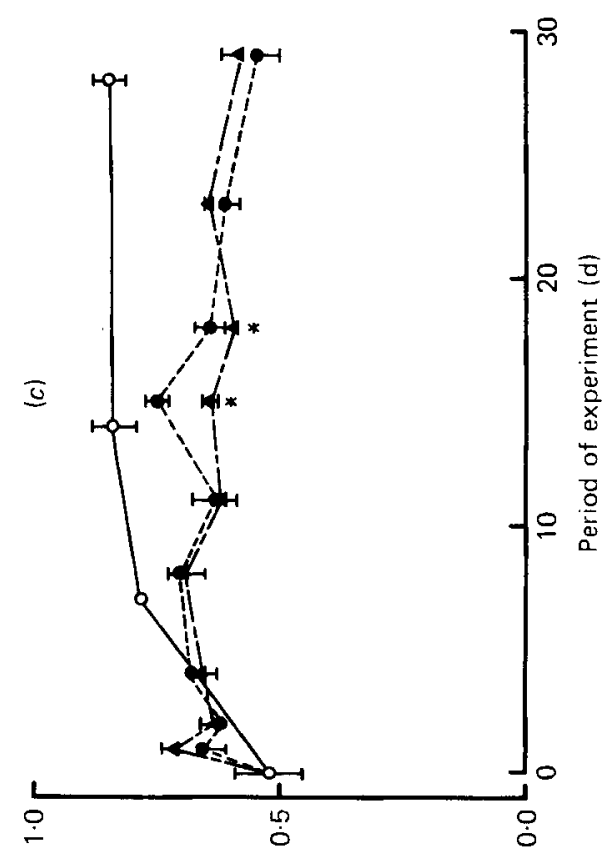

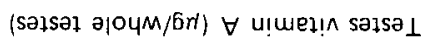

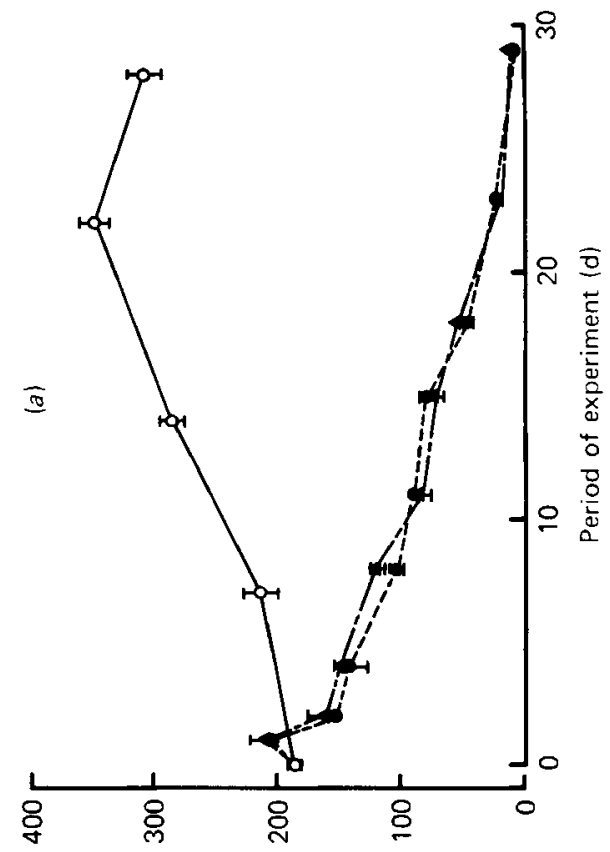

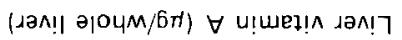

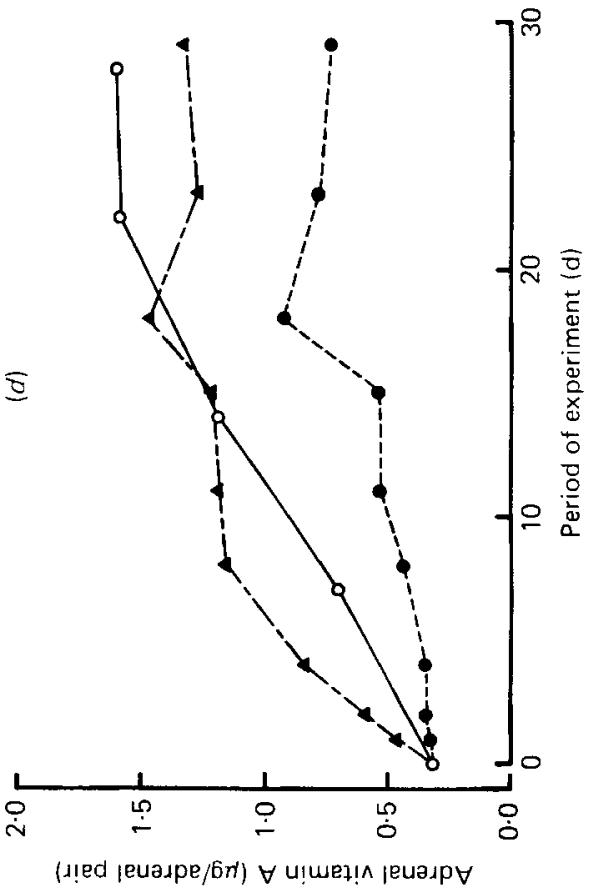

氝 큘 눈 능 恶主是 岁 छ형 要次

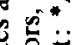
占 $\pm$ 已롱

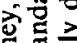
急芯到 问造

至 $\exists$ 选 ชิ 콩뭉 동웡

$<$ 昰

톯 늟

劳总

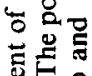
응 영 䒕的它. 융․ 党总 한

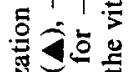

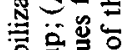
구ㅇㅡㅡ

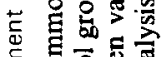
토융

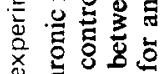

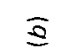

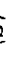

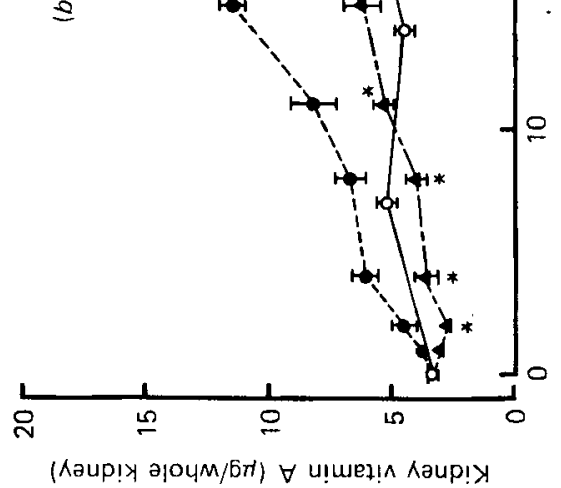

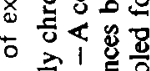
충

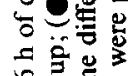
论

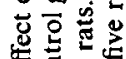
守吉 E皆 i t 0 它宇密 
as a function of time on diet in both the $+\mathrm{A}$ control rats and the $-\mathrm{A}$ control animals, although the magnitude of the increase was far less in the latter. Chronic immobilization for $6 \mathrm{~h}$ markedly accelerated this increase in the adrenal vitamin A content, although the rats were fed on a vitamin A-free diet ( - A stress). A plateau, reached on the 8 th $d(293 \%)$, was maintained through the last days of the experiment.

\section{DISCUSSION}

It has been repeatedly shown that the serum concentration of vitamin A falls in rats and humans when they are suffering from a variety of stresses such as surgical operation (Ramsden et al. 1978), myocardial infarction (Ramsden et al. 1978), burn injury (Rai \& Coutemanche, 1975), fever (Aron et al. 1946; Kagan \& Kaiser, 1955) and physical training (Barisov, 1977). However, there is little detailed information presently available establishing the mechanism regulating these processes. Ramsden et al. (1978) have recently suggested that the decline in the serum concentration of vitamin A which was provoked by the acute stress of surgical operation or myocardial infarction is due to either increased diffusion of the vitamin into peripheral tissues to satisfy increased cellular demand under these conditions or an incidental urinary loss of the vitamin, or both.

The results obtained in the present study confirm the previous findings in that chronic stress caused lowering in the serum content of vitamin A, although the magnitude of fall was somewhat small (Fig. 2). This was substantiated furthermore in our subsequent study where another type of confinement stress with greater intensity, fixation of the limbs of animals on a piece of board, was imposed on rats (Morita \& Nakano, unpublished results). It is unlikely that this decline in serum level of vitamin $\mathbf{A}$ is due to retardation of transport of the vitamin from liver storage since immobilization produced no appreciable change in the hepatic content of the vitamin (Fig. 3(a)) as compared with that in the -A control group. These results agree with the earlier observations of Sundaresan et al. (1967) who noted that total vitamin A content in the liver remained unchanged in rats suffering from cold-exposure stress.

Previously, High (1954) proposed that the kidney plays an important role in conserving vitamin A during the middle stage of vitamin A-depletion. This view was deduced from the finding that the content of vitamin $A$ in the kidney rose significantly although the animals were fed on a vitamin A-deficient diet. Confirming this previous finding, it was shown here that the kidney accumulated a significant amount of vitamin $A$ in the rats fed on a vitamin A-deficient diet, which level exceeded the hepatic content of vitamin $A$ after $29 \mathrm{~d}$ of the diet $(12.8 \pm 1.5 \mu \mathrm{g} /$ whole kidney and $10.1 \pm 1.2 \mu \mathrm{g} /$ whole liver $)$. It is noteworthy that imposing confinement stress on these rats caused a marked inhibition of this increase in the renal content of the vitamin (Fig. 3(b)). The results are compatible with those obtained by Odagiri \& Koyanagi (1961) who observed that the renal content of vitamin A decreased in rats suffering from cold-exposure stress. It seems just possible that the fall in the renal content of vitamin A might be a result of lowered serum concentration. However, as the testicular content of vitamin A, which is generally considered to be governed by blood vitamin A, remained unchanged following chronic confinement stress (Fig. 3(c)), reduction of renal vitamin A might be caused by other factors. In this connection, Ramsden $e t$ al. (1978) have recently suggested that a decline in serum content of vitamin $A$ in men suffering from surgical stress is due to an incidental urinary loss of the vitamin. It is likely, therefore, that the reduction in renal content of vitamin $A$ is not a result of lowered serum concentration of the vitamin but reflects its increased urinary loss, which conversely causes a decrease in serum vitamin A concentration.

As shown in Fig. $3(d), 6 \mathrm{~h}$ daily consecutive immobilization caused a preferential 
accumulation of vitamin $A$ in the adrenal glands although the rats were fed on a vitamin A-free diet (-A stress). These results are in accordance with those obtained by Glick $e t$ al. (1966) that electric foot shock, in combination with partial fasting, caused a significant elevation of vitamin $A$ in the adrenal glands of rats. They also observed parallelism between the post-partum increase in ability of rat adrenal cortex to respond to ACTH, resulting in a rise in serum concentration of corticosterone, and that of adrenal vitamin A content (Levine et al. 1967). On the other hand, Sundaresan \& Sundaresan (1975) have shown that vitamin $\mathrm{A}$ is most preferentially accumulated in the adrenal glands in the earliest stage after administration of a small amount of the vitamin to vitamin A-deficient rats. Based on these findings, Glick et al. (1966) and Sundaresan \& Sundaresan (1975) suggested an important function of vitamin A in this organ, e.g. in regulation of steroid hormone dynamics. The results obtained in the present study would provide a support to their view.

In conclusion, the results of the present study established that chronic immobilization stress provoked marked changes in the content of vitamin A in serum, kidneys and adrenal glands, whereas it caused no significant change in its hepatic and testicular content.

\section{REFERENCES}

Aron, H. C. S., Craig, R. M., Farmer, C. J., Kendel, H. W. \& Schwemlein, G. X. (1946). Proc. Soc. exp. Biol. Med. 61, 271.

Barisov, I. F. (1977). Teor. Prokt. Fiz. Kul't. p. 58.

Dugan, R. E., Frigerio, N. A. \& Seibert, J. M. (1964). Analyt. Chem. 36, 114.

Ershoff, B. H. (1950). Proc. Soc. exp. Biol. Med. 74, 586.

Ershoff, B. H. (1952). Proc. Soc. exp. Biol. Med. 79, 580.

Glick, D., Nakane, P. K., Levine, S. \& Jones, L. (1966). Endocrinology 78, 945.

Harper, A. E. (1959). J. Nutr. 68, 405.

Hepner, R. \& Maiden, N. C. (1971). Nutr. Rev. 29, 219.

High, H. G. (1954). Archs biochem. Biophys. 49, 19.

Kagan, B. M. \& Kaiser, E. (1955). J. Nutr. 57, 277.

Levine, S., Glick, D. \& Nakane, P. K. (1967). Endocrinology 80, 910.

Odagiri, S. \& Koyanagi, T. (1961). J. Vitam. 7, 86.

Page, H. M., Erwin, E. S. \& Nelms, G. E. (1959). Am. J. Physiol. 196, 917.

Porter, E. \& Masoro, E. J. (1961). Proc. Soc. exp. Biol. Med. 108, 609.

Rai, K. \& Coutemanche, A. D. (1975). J. Trauma. 15, 419.

Ramsden, D. B., Price, H. P., Burr, W. A., Bradwell, A. R., Black, E. G., Evance, A. E. \& Hoffenberg, H. (1978). Clin. Endocr. 8, 109.

Selye, H. (1946). J. clin. Endocr. 6, 117.

Selye, H. (1976). Stress in Health and Disease, Boston, Massachusetts: Butterworths Inc.

Snedecor, G. W. \& Cochran, W. G. (1967). Statistical Methods, 6th ed., Ames Iowa: The Iowa State College Press. Sundaresan, P. R. \& Sundaresan, G. H. (1975). Biochem. J. 152, 99.

Sundaresan, P. R., Winters, V. G. \& Therriault, D. G. (1967). J. Nutr. 92, 474.

Thompson, J. N., Erdody, F., Brien, R. \& Murray, T. K. (1971). Biochem. Med. 5, 67.

Underwood, B. A., Loerch, J. D. \& Lewis, K. C. (1979). J. Nutr. 109, 796. 